\title{
Evaluation of Dri-Dot OMPs Salmonella Typhi in Suspected Typhoid Fever Patients as an Immunodiagnostic Kit
}

\author{
Yusriani Mangarengi ${ }^{1,5}$, Ressy Dwiyanti², Nataniel Tandirogang ${ }^{3}$, Muhammad Sabir ${ }^{2}$, \\ Rosdiana Natzir ${ }^{4}$, Mochammad Hatta ${ }^{5}$, Yadi ${ }^{3 . *}$ \\ ${ }^{1}$ Department of Microbiology, Faculty of Medicine, Muslim University of Indonesia, Makassar, Indonesia \\ ${ }^{2}$ Department of Microbiology, Faculty of Medicine, Tadulako University, Palu, Indonesia \\ ${ }^{3}$ Department Microbiology and Immunology, Faculty of Medicine, Mulawarman University, Samarinda, Indonesia \\ ${ }^{4}$ Department of Biochemistry, Faculty of Medicine, Hasanuddin University, Makassar, Indonesia \\ ${ }^{5}$ Molecular Biology and Immunology Laboratory for Infectious Diseases, Faculty of Medicine, Hasanuddin University, Makassar, Indonesia
}

\section{Email address:}

yusrianiaris@yahoo.com (Y. Mangerangi), ressy_chan@yahoo.co.id (R. Dwiyanti), tandirogang@yahoo.com (N. Tandirogang), destadamba@yahoo.com (M. Sabir), rosdianarnatzir@yahoo.com (N. Rosdiana), hattaram@indosat.net.id (M. Hatta), dryadi02@yahoo.com (Yadi)

\section{To cite this article:}

Yusriani Mangarengi, Ressy Dwiyanti, Nataniel Tandirogang, Muhammad Sabir, Rosdiana Natzir, Mochammad Hatta, Yadi. Evaluation of Dri-Dot OMPs Salmonella Typhi in Suspected Typhoid Fever Patients as an Immunodiagnostic Kit. American Journal of Biomedical and Life Sciences. Vol. 3, No. 4, 2015, pp. 87-90. doi: 10.11648/j.ajbls.20150304.14

\begin{abstract}
Background. Several studies have identified a protein of OMP S. Typhi. The protein is highly immunogenic and can be recognize whole cells of S. Typhi. The aims of the study was to evaluate the Dri-dot OMPs immunoreactivity in typhoid fever suspected patients. Method. Samples obtained from Dr. Wahidin Sudirohusodo Hospital, lbnu Sina Hospital, and Haji Hospital of Makassar from February to November 2014. Their sensitivity and specificity were evaluated against blood culture method as the gold standard. For each of the two tests, sensitivity, specificity, positive and negative predictive values were calculated using standard formulae. Results. A total of 15 of suspected typhoid fever samples examined for culture, lateral flow and Dri-dot OMPs. Examination of blood culture method showed that 3 of 15 (20\%) patients had a blood culture positive for S. typhi. Dri-dot OMPs were positive in $13(86.7 \%)$ serum samples. Fourteen $(93.3 \%)$ serum samples were positive for lateral flow examination. Thirteen samples were positive for both Dri-dot and lateral flow. One sample was negative for both lateral flow and Dri-dot. One sample was positive for Dri-dot but negative for lateral flow. Conclusion. We conclude that there was no difference between Dri-dot OMPs, lateral flow and widal tests. Dri-dot could be of use for the diagnosis of typhoid fever in patients who have clinical typhoid fever.
\end{abstract}

Keywords: Salmonella Typhi, Typhoid Fever, Lateral Flow, Dri-Dot OMPs

\section{Background}

Typhoid (enteric) fever is still a common disease in many developing countries but current diagnostic tests are inadequate [1]. Typhoid fever is responsible for an estimated yearly burden of $16,591,000$ cases and 580,000 deaths worldwide. The greatest burden of illness occurs in Asia, where 13,310,000 cases and 440,000 deaths occur annually [2]. Typhoid fever only found in its human host [3]. In the regions where enteric fever is common, clinical diagnosis of typhoid fever is inadequate, as the symptoms it causes are nonspecific and overlap with those of other febrile illness, such as vector-borne malaria, dengue fever and rickettsioses as well as environmentally transmitted leptospirosis and melioidosis $[4,5]$.

The clinical signs of uncomplicated typhoid fever are nonspecific, and an accurate diagnosis on clinical grounds alone is difficult. In developing countries most serotype Typhi infections are diagnosed purely on clinical grounds and treated presumptively. As a result, the diagnosis may be delayed or missed while other febrile illnesses are considered, and patients without typhoid fever may receive unnecessary and inappropriate antimicrobial therapy [6]. Although a definitive diagnosis can be made by isolation of $S$. typhi from blood or bone marrow, but in endemic areas such as Indonesia, bacterial culture facilities are often unavailable [7]. 
Detection of serum antibodies using the Widal test, which is currently the standard serological method for typhoid diagnosis. However, this method is relatively low specificities [8]. Need some efforts to develop faster and more sensitive and specific serological assays for the diagnosis of typhoid fever.

Previous study, has been addressed to the role of the outer membrane proteins (OMPs) of gram-negative bacteria in the induction of specific immunity. The results of this study indicate the usefulness of OMPs in the induction of active immunity against $S$. typhi in mice [9]. Outer membrane proteins was found to be immunogenic and capable of stimulating both humoral mucosal and systemic immunity. Outer membrane proteins was also able to stimulate cellular immune responses [10]. Because of its ability to stimulate the immune response and protection against bacterial adhesion, we investigated OMPs as a diagnostic tool for typhoid fever.

\section{Methods}

\subsection{Isolation of S. Typhi Strain}

Virulent S. typhi was originally isolated from a patient with typhoid fever. Five $\mathrm{mL}$ of patient blood was taken aseptically and then inserted into the BACTEC transport medium and incubated at $37^{\circ} \mathrm{C}$ for $24-48$ hours. This culture were then incubated on selective medium (MacConkey) at $37^{\circ} \mathrm{C}$ for $18-24$ hours. Identification of $S$. typhi was carried out by its colony characteristic on culture medium. Biochemical and microscopic tests (Gram's staining) were performed to confirm the presence of $S$. thypi $[11,12]$.

\subsection{Isolation of OMPs}

Salmonella OMPs were extracted by following protocol described by S. Kim et al (2006) [13]. In brief, 6-8 ose culture of $S$. typhi was added to BHIB $1 \mathrm{ml}$ of medium and incubated at $37^{\circ} \mathrm{C}$ for 24 hours. Furthermore, the cell cultures were centrifuged at $15,000 \mathrm{~g}$ for $20 \mathrm{~min}$ at $4^{\circ} \mathrm{C}$. The pellets then added with $10 \mathrm{mM} 11$ Tris- $\mathrm{HCl}(\mathrm{pH} 8)$ and sonicated on ice using a sonicator for 4 times for 5 seconds [14], centrifuged at $15,000 \mathrm{~g}$ for $1 \mathrm{~h}$ at $4^{\circ} \mathrm{C}$. Returned pellets were separated and added with $10 \mathrm{~mL}$ of $10 \mathrm{mM} \mathrm{1-1} \mathrm{Tris-} \mathrm{HCl}(\mathrm{pH} 8)$ and sarcosyl to reach a final concentration of $1.5 \%(\mathrm{v} / \mathrm{v})$. After $20 \mathrm{~min}$ at room temperature, the outer membranes were collected by centrifugation at $15,000 \mathrm{~g}$ for $90 \mathrm{~min}$ at $4^{\circ} \mathrm{C}$. We use the outer membranes protein to activate the latex beads (Dri-dot OMPs).

\subsection{Evaluation of Diagnostic Accuracy of the Rapid Kits}

The results from the two rapid kits were evaluated against blood culture method as the gold standard. For each of the two tests, sensitivity, specificity, positive and negative predictive values were calculated using standard formulae. Sensitivity, which is the percentage of positive individuals correctly identified as such, was calculated using the formula: Sensitivity $=$ number of true positives $(\mathrm{TP}) /($ number of TP + number of false negatives $(\mathrm{FN})) \times 100 \%$. Specificity, which is the percentage of negative individuals correctly identified as such, was calculated with the formula: Specificity = number of true negatives $(\mathrm{TN}) /($ number of $\mathrm{TN}+$ number of false positives $(\mathrm{FP})) \times 100 \%$. Positive predictive value $(\mathrm{PPV})$, the proportion of positive test results that are truly positive, was calculated using the formula: $\mathrm{PPV}=\mathrm{TP} /(\mathrm{TP}+\mathrm{FP}) \times$ $100 \%$, and the negative predictive value (NPV), which is the proportion of negative test results that are truly negative was calculated using the formula: $\mathrm{NPV}=\mathrm{TN} /(\mathrm{TN}+\mathrm{FN}) \times$ $100 \%$.[13] Patients in this study had symptoms and signs of typhoid, which included persistent and high fever $\left(>38^{\circ} \mathrm{C}\right.$ oral temperature), chills malaise, headache, sore throat, cough and sometimes abdominal pain and constipation or diarrhea. Fifteen samples of suspected typhoid fever were examined using Dri-dot OMPs, lateral flow test and bacterial culture.

\subsection{Ethical Approval and Informed Consent}

Institutional and ethical permission to carry out the study was obtained from the Faculty of Medicine Hasanuddin University Makassar Indonesia. Adult participants and parents/guardians of sick children provided by informed consent before blood samples were collected.

\section{Results}

Table 1. Blood culture in patients suspected of typhoid fever.

\begin{tabular}{llll}
\hline & & $\mathbf{N}$ & $\mathbf{\%}$ \\
\hline \multirow{3}{*}{ Culture } & Positive & 3 & 20 \\
& Negative & 12 & 80 \\
& Total & 15 & 100 \\
\hline
\end{tabular}

Table 2. Dri-dot OMPs results in serum samples of typhoid fever patients.

\begin{tabular}{llll}
\hline & & $\mathbf{N}$ & $\mathbf{\%}$ \\
\hline \multirow{2}{*}{ Dri-dot } & Positive & 13 & 86.7 \\
OMPs & Negative & 2 & 13.3 \\
& Total & 15 & 100 \\
\hline
\end{tabular}

Table 3. Lateral flow results in serum samples of typhoid fever patients.

\begin{tabular}{llll}
\hline & & $\mathbf{N}$ & $\mathbf{\%}$ \\
\hline \multirow{2}{*}{ Lateral } & Positive & 14 & 93.3 \\
Flow & Negative & 1 & 6.7 \\
& Total & 15 & 100 \\
\hline
\end{tabular}

Table 4. Sera from typhoid fever patients examined by Dri-dot OMPs and Lateral flow.

\begin{tabular}{lllll}
\hline & & \multicolumn{2}{l}{ Dri-dot OMPs } & Total \\
\cline { 3 - 5 } & & Positive & Negative & 14 \\
\hline \multirow{2}{*}{ Lateral } & Positive & 13 & 1 & 1 \\
Flow & Negative & 0 & 1 & 15 \\
& Total & 13 & 2 & \\
\hline
\end{tabular}

A total of 15 samples examine for culture, lateral flow and Dri-dot OMPs. Examination of blood culture method showed that 3 of $15(20 \%)$ patients had a blood culture positive for $S$. typhi. The results of the culture examination are presented in Table 1. Dri-dot OMPs were positive in 13 serum samples. 
The results of the Dri-dot OMPs examination are presented in Table 2. Fourteen serum samples were positive for lateral flow examination (Table 3). Thirteen samples were positive for both Dri-dot OMPs and lateral flow. One sample was negative for both lateral flow and Dri-dot OMPs. One sample was positive for Dri-dot OMPs but negative for lateral flow as shown in Table 4.

Table 5. Comparative evaluation of Dri-dot OMPs and Lateral flow (if blood culture as a gold standard).

\begin{tabular}{lllllll}
\hline & $\begin{array}{l}\text { No. of positive among No. of positive among negative } \\
\text { positive culture cases }(\mathbf{n = 3})\end{array}$ & $\begin{array}{l}\text { Sensitivity } \\
\text { culture cases }(\mathbf{n}=\mathbf{1 2})\end{array}$ & $\begin{array}{l}\text { Specificity } \\
\text { vositive predictive } \\
\text { value }\end{array}$ & $\begin{array}{l}\text { Negative } \\
\text { predictive value }\end{array}$ \\
\hline Dri-dot OMPs & $3(100 \%)$ & $10(83.3 \%)$ & $100 \%$ & $16.7 \%$ & $23.1 \%$ \\
Lateral Flow & $3(100 \%)$ & $11(91.7 \%)$ & $100 \%$ & $8.3 \%$ & $21.4 \%$ & $100 \%$ \\
\hline
\end{tabular}

\section{Discussion}

This study was conducted during the period of February to November 2014. As many as 15 patients clinically suspected typhoid fever were included in this study. Samples were obtained from Ibnu Sina Makassar Hospital, Dr. Wahidin Sudirohusodo Hospital, Akademis Hospital and Haji Makassar Hospital.

Typhoid fever often causes severe mental clouding of consciousness and includes headache, anorexia and congestion of mucous membrane which result from toxic effects of $S$. typhi endotoxin. The definitive diagnosis of typhoid fever requires the isolation of organism from blood, bone marrow or rose spots [14-16]. Blood culture is considered as gold standard in the diagnosis of typhoid fever but it is a slow process, time consuming, its use is limited in early cases of fever, it becomes rapidly negative with administration of antibiotics and available in higher laboratories [14, 17].

The purpose of this study was to develop rapid diagnostic for typhoid fever using Dri-dot OMPs. We compared Dri-dot OMPs results with blood culture and lateral flow in suspected typhoid fever patients. In this study, among 15 widal positive serum samples we found only 3 samples positive by culture therefore, culture was positive in $20 \%$ of all cases with a clinical suspected of typhoid fever. Possible causes of this negative culture results in this study was the fact that most of the patients are likely to have taken antibiotics before seeking medical care at the hospital. It is commonly in developing country including Indonesia. Blood culture is highly sensitive to the presence of antibiotics in the sample [18]. We used blood culture-positive patients as a gold standard, because bone marrow culture as a gold standard is difficult to perform. The results presented here showed that all culture positive samples were positive on lateral flow and Dri-dot OMPs.

When using blood culture as gold standard, sensitivity of lateral flow and Dri-dot OMPs was $100 \%$ but specificity very low were $8.3 \%$ and $16.7 \%$ respectively. Positive predictive value of Lateral flow was $21.4 \%$ and positive predictive value of Dri-dot OMPs was $23.1 \%$. Lateral flow and Dri-dot OMPs had $100 \%$ of negative predictive value. The results presented here show that Dri-dot OMPs and lateral flow tests for the detection of IgM antibodies to serotype Typhi LPS perform no differences than the Widal test.

The antibody response to $S$. typhi as well as other infectious agent provides useful diagnostic markers of the infection caused in a host. Pathogen-specific IgM antibodies appear quickly within weeks after the infection but disappear soon afterward [19]. These tests could be of use for the diagnosis of typhoid fever in patients who have clinical typhoid fever but are culture negative or in regions where bacterial culturing facilities are not available [20].

Early diagnosis and complete treatments reduce the complications in typhoid fever [21]. In this study, we designed a new and rapid diagnostic method based on latex agglutination test (Dri-dot) using OMPs antigen to detect antibody anti-OMP in serum samples.

\section{Conclusion}

We conclude that there was no difference between Dri-dot OMPs, lateral flow and widal tests. Dri-dot OMPs could be of use for the diagnosis of typhoid fever in patients who have clinical typhoid fever.

\section{References}

[1] Baker S, Favorov M, Dougan G: Searching for the elusive typhoid diagnostic. BioMed Central Infectious Diseases 2010, 10(45).

[2] Yang HH, Kilgore PE, Yang LH, Park JK, Pan YF, Kim Y, Lee YJ, Xu ZY, Clemens JD: An outbreak of typhoid fever, XingAn County, People's Republic of China, 1999: estimation of the field effectiveness of Vi polysaccharide typhoid vaccine. The Journal of infectious diseases 2001, 183(12):1775-1780.

[3] Santiviago CA, Toro CS, Bucarey SA, Mora GC: A chromosomal region surrounding the ompD porin gene marks a genetic difference between Salmonella typhi and the majority of Salmonella serovars. Microbiology 2001, 147(Pt 7):1897-1907.

[4] Zhou L, \& Pollard: A fast and highly sensitive blood culture PCR method for clinical detection of Salmonella enterica serovar Typhi Annals of Clinical Microbiology and Antimicrobials 2010, 9( 14).

[5] Parry CM: Epidemiological and clinical aspects of human. In: Salmonella infections clinical, immunological and molecular aspects edn. Edited by P.Mastroeni DM. Cambridge: Cambridge University Press. ; 2006: 1-17.

[6] Olsen SJ, Pruckler J, Bibb W, Thanh NT, Trinh TM, Minh NT: Evaluation of rapid diagnostic tests for typhoid fever. Journal of clinical microbiology 2004, 42(5):1885-1889. . 
[7] Parry CM, Hoa NT, Diep TS, Wain J, Chinh NT, Vinh H, Hien TT, White NJ, Farrar JJ: Value of a single-tube widal test in diagnosis of typhoid fever in Vietnam. Journal of clinical microbiology 1999, 37(9):2882-2886.

[8] Fadeel MA, House BL, Wasfy MM, Klena JD, Habashy EE, Said MM, Maksoud MA, Rahman BA, Pimentel G: Evaluation of a newly developed ELISA against Widal, TUBEX-TF and Typhidot for typhoid fever surveillance. Journal of infection in developing countries 2011, 5(3):169175.

[9] Isibasi A, Ortiz V, Vargas M, Paniagua J, Gonzalez C, Moreno J, Kumate J: Protection against Salmonella typhi infection in mice after immunization with outer membrane proteins isolated from Salmonella typhi 9,12,d, Vi. Infection and immunity 1988, 56(11):2953-2959.

[10] Winarsih S: Cloning and expression gene Adhesin Adho36 of S.Typhi as candidate vaccines of Typhoid fever. . In: Report of Research RISTEK. 2007.

[11] MacConkey: Note on a new medium for the growth and differentiation of the bacillus coli communis and the bacillus typhi abdominalis. The Lancet 1900, 156(4010):172.

[12] CDC., WHO.: Manual for the Laboratory Identification and Antimicrobial Susceptibility Testing of Bacterial Pathogens of Public Health Importance in the Developing World. In.; (2003).

[13] Tarupiwa A, Tapera S, Mtapuri-Zinyowera S, Gumbo P, Ruhanya V, Gudza-Mugabe M, Majuru NX, Chin'ombe N: Evaluation of TUBEX-TF and OnSite Typhoid IgG/IgM Combo rapid tests to detect Salmonella enterica serovar Typhi infection during a typhoid outbreak in Harare, Zimbabwe. $B M C$ research notes $2015,8: 50$.

[14] Arjunan M, Al-Salamah AA: Typhoid fever with severe abdominal pain: diagnosis and clinical findings using abdomen ultrasonogram, hematology-cell analysis and the Widal test. Journal of infection in developing countries 2010, 4(9):593-596.
[15] Sheikh A, Bhuiyan MS, Khanam F, Chowdhury F, Saha A, Ahmed D, Jamil KM, LaRocque RC, Harris JB, Ahmad MM et al: Salmonella enterica serovar Typhi-specific immunoglobulin A antibody responses in plasma and antibody in lymphocyte supernatant specimens in Bangladeshi patients with suspected typhoid fever. Clinical and vaccine immunology : CVI 2009, 16(11):1587-1594.

[16] 16. Song JH, Cho H, Park MY, Na DS, Moon HB, Pai CH: Detection of Salmonella typhi in the blood of patients with typhoid fever by polymerase chain reaction. Journal of clinical microbiology 1993, 31(6):1439-1443.

[17] Hansen KR, Nielsen LR, Lind P: Use of IgG avidity ELISA to differentiate acute from persistent infection with Salmonella Dublin in cattle. Journal of applied microbiology 2006, 100(1):144-152.

[18] Smith SI, Bamidele M, Fowora M, Goodluck HT, Omonigbehin EA, Akinsinde KA, Fesobi T, Pastoor R, Abdoel TH, Smits HL: Application of a point-of-care test for the serodiagnosis of typhoid fever in Nigeria and the need for improved diagnostics. Journal of infection in developing countries 2011, 5(7):520-526.

[19] Mahbubur Rahman, Siddique AK, Tam FC-H, Sabrina Sharmin, Harunur Rashid, Anwarul Iqbal, Sirajuddin Ahmed, Gopinath Balkrish Nair, Claire-Lise Chaignat, Lim P-L: Rapid detection of early typhoid fever in endemic community children by the TUBEX O9-antibody test. Diagnostic microbiology and infectious disease 2007.

[20] House D, Wain J, Ho VA, Diep TS, Chinh NT, Bay PV, Vinh H, Duc M, Parry CM, Dougan G et al: Serology of typhoid fever in an area of endemicity and its relevance to diagnosis. Journal of clinical microbiology 2001, 39(3):1002-1007.

[21] Safari Foroshani N, Karami A, Pourali F: Simultaneous and Rapid Detection of Salmonella typhi, Bacillus anthracis, and Yersinia pestis by Using Multiplex Polymerase Chain Reaction (PCR). Iranian Red Crescent medical journal 2013, 15(11):e9208. 